Michael Anker, Digital leder, Ballerup Bibliotek, mank@balk.dk

Thomas Sture Rasmussen, Innovations- og strategiudvikler, Ballerup Bibliotek, tsr@balk.dk

\title{
Ballerup Bibliotekernes Makerspace
}

\section{- Eksempel fra praksis}

Bibliotekets formål er at fremme oplysning, uddannelse og kulturel aktivitet som beskrevet i biblioteksloven (Kulturministeriet, 2013). Det gør vi allerede i stor stil ved at stille fysiske og elektroniske materialer til rådighed. Men med Ballerup Bibliotekernes Makerspace går vi skridtet videre ved også at stille den nyeste teknologi til rådighed for borgerne for at skabe nye fællesskaber omkring læring og innovation.

Ballerup Bibliotekernes kerneopgave er defineret som: "Vores kerneopgave er at formidle kultur, viden og oplevelser i et frirum, hvor borgerne er medskabere. Vi er stifindere og skaber sammenhængskraft."

Ballerup Bibliotekernes Makerspace er i høj grad med til at understøtte kerneopgaven, bibliotekets formål, samt Ballerups Vision 2029 (Ballerup Kommune, u.å.) som har udpeget 4 temaer ("Åben for nye idéer", "En stærk uddannelsesby", "En grøn by i balance", "En førende erhvervsby" samt hovedtemaet "Vi skaber fremtiden sammen").

Vi er ikke et Hackerspace eller Fablab, da det ville begrænse vores maskinpark og tilgang (Cavalcanti, 2013). Makerspaces har et bredere fokus, som ikke tager udgangspunkt i en bestemt maskinpark eller elektronik. Det har blandt andet betydet at Ballerup Bibliotekernes Makerspace indgår som en mere naturlig del af Ballerup biblioteks aktiviteter og dannelsesprojekt.

Kernen af vores Makerspace er et værksted, som alle kan lære at bruge. Her kan du både møde kreative sjæle, iværksættere, pensionister, teknologi-interesserede, børnefamilier, jobsøgende, studerende, foreninger og andre nysgerrige mennesker.

Maskinparken består af en lang række maskiner, der kan understøtte og virkeliggøre borgernes ideer. Der er både maskiner til at lave fysiske prototyper som 3D printer, laserskærer, CNS-fræser, storformatprinter og computere med programmer til at skabe digital grafik.

Budgettet for at opretholde et Makerspace er omkring $65.000 \mathrm{kr}$. om året. Budgettet indeholder udgifter og indtægter på materialer, supportaftaler, softwarelicenser, arrangementsudgifter til materialer, småindk $\varnothing \mathrm{b}$ af nyt 
værktøj/maskiner og vedligehold. Budgettet indeholder ikke afviklingsudgifter på maskiner eller personaleudgifter.

\section{Digital Dannelse}

Ballerup Bibliotekerne arbejder med digital dannelse og er blevet inspireret af Dansk IT's anbefalinger (SteenHansen, 2016) til styrkelsen af danskernes digitale kompetencer, som er udarbejdet sammen med Danmarks Biblioteksforening (ibid.) i 2016. Anbefalingerne er stadig et udkast.

Anbefalingerne består af

Digitale brugerkompetencer:
Kende til og forstå digitale værktøjer
At besidde grundlæggende tekniske
færdigheder og viden.
Tilgå og evaluere information
At kunne finde, hente samt bedømme
relevans, integritet og brugbarhed.
Håndtere information
At kunne kategorisere, organisere og
lagre information på en effektiv og
genbrugelig måde.

Digitale skaberkompetencer:
Omdanne information
At kunne tage afsæt i, udvælge og
omdanne tekst til bestemte formăl.
Skabe information
At designe og udarbejde it-produkter til
bestemte mălgrupper og formål.
Dele information
At kunne forstå og bruge digitale
værktøjer til at samarbejde,
kommunikere og udveksle informationer.
Konstruere
At kunne forstå og bruge strukturer og
algoritmer, herunder at forholde sig
skabende til dem.

Refleksive digitale kompetencer:

Anvende information trygt

At kunne forstå og håndtere etiske og

lovmæssige problemstillinger i forbindelse med digitalt baseret kommunikation.

Identitetsskabelse

At kunne agere hensigtsmæssigt i forhold til, hvordan man ønsker at fremtræde som et digitalt formidlet individ.

\section{Samfundsforståelse}

At kunne forstå hvordan den digitale udvikling påvirker samfundet og dets institutioner og virksomheder.

\section{Digital dannelse}

At kunne udfolde sig og deltage i alle samfundsmæssige forhold.

Anbefalingerne har været med til at skabe et overblik over de mange digitale tilbud vi tilbyder: IT-hjælp, debatarrangementer om digital sikkerhed, udvikling af tilbud til læsesvage, underst $\varnothing t$ tet læseglæde ved hjælp af en humanoid robot, samt vores Makerspace-tilbud.

\section{Maker-fokus}

Man kan groft opdele maker-bevægelsen inden for udviklingen af 4 hovedområder: Digital prototype, Elektronik, Tekstil og Håndværk. I Ballerup Bibliotekernes Makerspace har vi fokuseret på Digital prototypeudvikling samt elektronik. Vi udvidede med elektronik-indsatsen efter halvandet år.

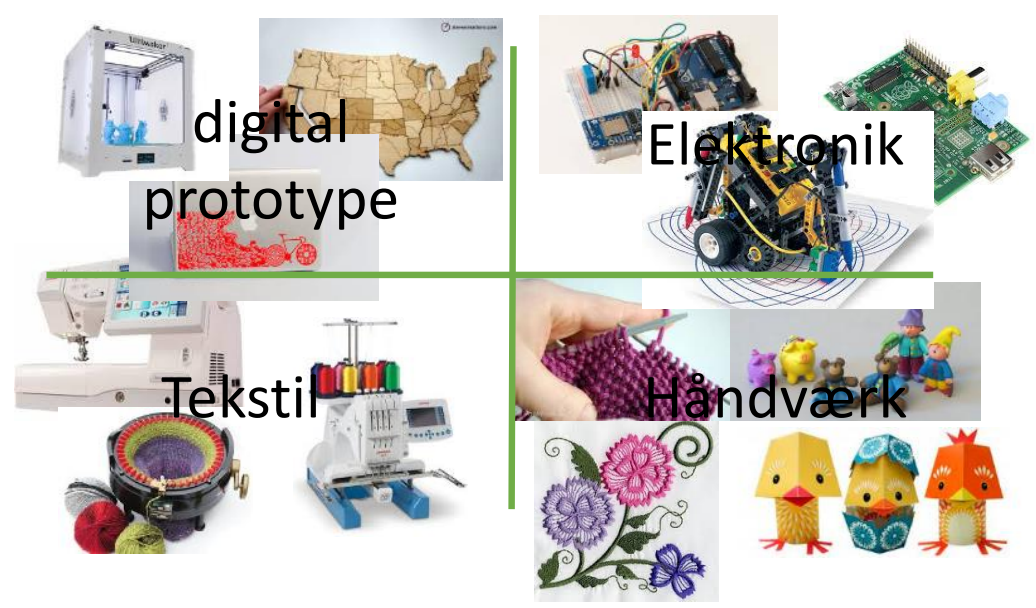


Elektronik-delen er hovedsagelig aktivitetsbaseret med events inden for f.eks. Lego Mindstorm (Lego Group, u.å.), Lego Art Machines (Ryan, 2016), Little Bits (Littlebits Electronics Inc., u.å.), Ultra:Bit (DR, u.å.) og Arduino (Arduino, 2018).

Digital prototype-delen underst $\varnothing$ tter vi med Åbent Hus, hvor vores åbningstid er 13-19 mandag til torsdag, samt Iørdag en gang om måneden fra 10-14. Næste år udvider vi lørdagsåbent til alle lørdage, da det har vist sig at være en stor succes. I åbningstiden står bibliotekets ansatte klar til at give en hånd med at bruge stedets maskiner. Maskinerne kræver, at man bliver introduceret til deres muligheder og begrænsninger, før man kan bruge dem. Personalet udfører ikke, men underst $\varnothing$ tter det borgeren gerne vil skabe. Alle er velkommen til at komme ned og arbejde eller bare se værkstedet i vores betjente åbningstid, og borgerne behøver ikke at reservere tid for at bruge stedet eller maskinerne.

Derudover holdes introkurser, som afholdes af vores kompetente gruppe af frivillige. Introkurserne foregår en gang om måneden (undtaget ferierne). Vi afholder desuden kurser til folkebiblioteket som led i folkeskolereformen, hvor folkeskolen som led af de nye læringsmål skal inddrage virksomheder, foreningen og andre interessenter i deres undervisning (SIV, u.å.). Derudover afholder vi aktiviteter i alle ferierne. Typisk et arrangement om dagen. Arrangementerne har bestået af f.eks. Makey Makey hvor man spiller arkadespil på bananer eller lignende, 3D print af fidget spinners eller bogmærker, 3D skanning af dig selv med efterfølgende 3D print, sæbebobletryllestave, højtalere af toilet og køkkenruller til din smartphone, kuglebaner, vinyltryl på tshirts, samt lav dine egne smykker og badges.

Borgerne kan lære maskinerne og softwaren at kende og udvikle kompetencer inden for fremstilling med digitale redskaber. Fokus er derfor på forløbet fra idé til færdig model og ikke på produktion, og som bruger må du derfor kun lave et enkelt eksemplar af deres design. Vi har derfor også begrænset materialerne til prototype-udvikling og ikke færdige produkter.

\section{De fysiske rammer for Makerspace}

Makerspace består af 5 rum: Showroom med plads til leg og læring, maskinpark, undervisningslokale, mødelokale og et rum til laserskærer og CNC-fræser. Disse rum understøtter alle forskellige dele af den innovative proces og er indrettet derefter. Rummene er i konstant udvikling og der er blevet foretaget 3-4 større indretninger på 3 år.

Fra at have haft maskinparken i makerspace i fokus, har vi, inspireret af det arbejde som Future Classroom Lab laver med makerspaces i folkeskolen (Future Classroom Lab., u.å.), herunder udvikling af nye læringsbegreber (21skills (Center for Undervisningsmidler, 2018)), ændret lidt på vores tilgang til brugen af makerspace. Leg og læring er kommet lidt mere i fokus i stedet for maskinerne, så brugerne kan starte ud med materialer og færdigheder de allerede kender og besidder. Og først i næste led introduceres de for maskinerne, der hvor det giver mening. På den måde kan leg med Lego føre til Lego Mindstorm, Tegning og piberenser til 3D print, osv.

Hovedrummet er dog stadig maskinparken som er indrettet som et værksted og har et større arbejdsbord i midten af rummet.

\section{Hvordan lykkedes vi}

De frivillige spiller en stor rolle i Ballerup Bibliotekernes Makerspace i form af afholdelse af de mange introkurser, der efter 3 år stadig er en stor succes. For at benytte sig af maskinparken kræver det nogen grundlæggende færdigheder som alle har mulighed for at lære på introkurserne.

For at sikre sammenhængskraften med biblioteket er der indsat personale til at afholde åbent hus og afholde aktiviteter. Dette har krævet en længerevarende kompetenceudvikling. For at understøtte denne proces har Maker-gruppen i fællesskab udarbejdet et kompetencespind med 3 niveauer, fra laveste niveau (centrum) til 
højeste niveau (yderst), gående fra kendskab til kunne og mestre. Kompetencespindet bliver udfyldt som led i de årlige medarbejdersamtaler (MUS), og der er udarbejdet makerskills som alle skal kunne.

\section{Kompetencespind for rollen \\ Makerspacevagt}

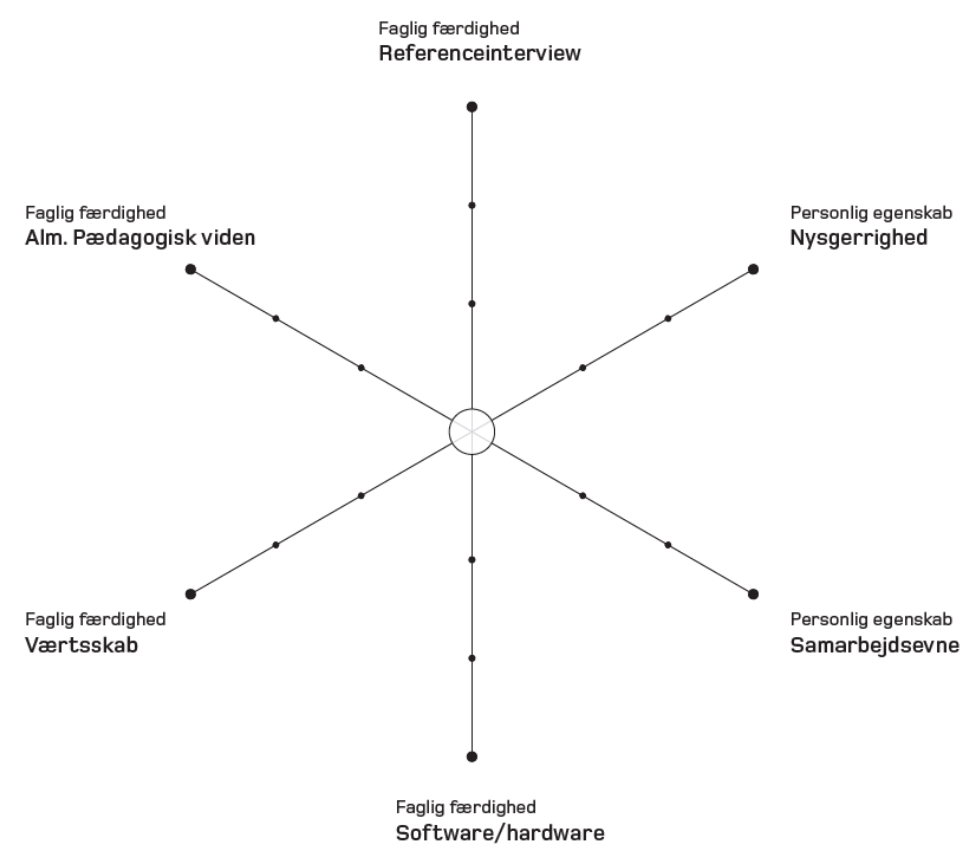

\section{FAGLIG FAERDIGHED}

\begin{tabular}{l} 
Referenceinterview \\
Opgavevurdering \\
Begrænsninger \\
Inspiration \\
\\
\hline
\end{tabular}

\section{FAGLIG FAERDIGHED}

\section{Værtskab}

Elevatortale

Opsøgende

Facilitator / Henvise

Lokalkendskab

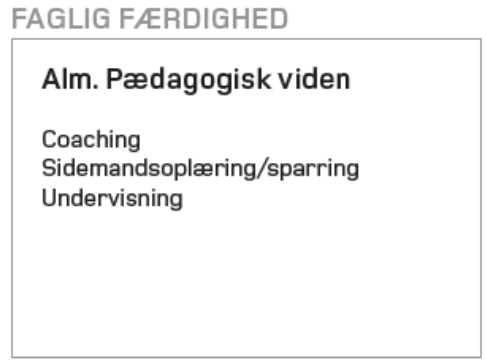

\section{FAGLIG FAERDIGHED}

\section{Software/hardware}

Maskiner

Materialer

Programmer

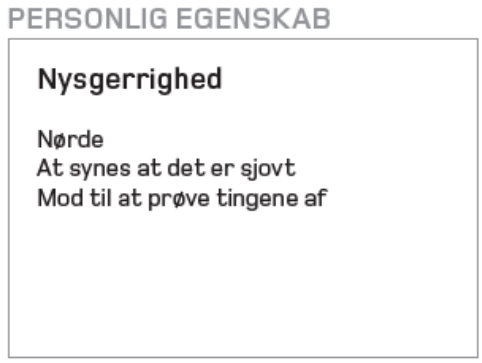

\section{PERSONLIG EGENSKAB}

\section{Samarbejdsevne}

Tværfagligt

Sparring og videndeling

Fx. at se muligheder $\mathrm{i}$ at kombinere

fagligeheder og samarbejde mellem

for eksempel skøn og børn eller

Makerspace og Lab 


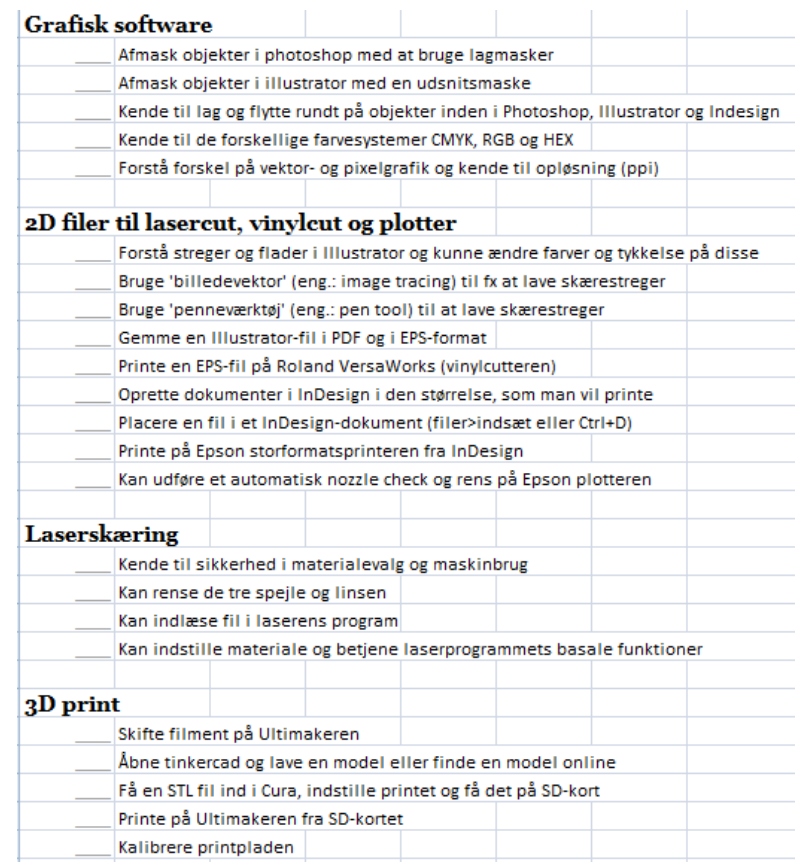

Der er sikret en bred personalesammensætning bestående af klassiske bibliotekariske profiler (børne-, og voksenbibliotekar) til andre akademiske profiler. Dette har gjort at Makerspace er en fuldt ud integreret del af biblioteket og ikke et biprodukt.

\section{Fremtiden}

Ballerup Bibliotekernes Makerspace er i konstant udvikling. Maskinparken udvides med nye maskiner, der skal nye kompetencer til og vi indgår nye samarbejder. I 2018 forventer vi at 500 børn, 800 folkeskoleelever og 300 borger vil gøre brug af makerspace.

I forbindelse med Ballerup Biblioteks samarbejde med innovationsuddannelsen på DTU, som blev indgået sidste år, har studerende kodet vores humanoide Pepper robot (Softbank Robotics America, Inc., 2018) til at kunne vise rundt i makerspace. Bl.a. kan den fortælle om vores 3D printere, laserskærer mv.

I efteråret 2019 gennemfører vi er innovationsforløb i makerspace i samarbejde med det lokale gymnasium Borupgaard og DTU Diplom. Her skal de studerende sammen med borgere i Ballerup udvikle prototyper der relaterer sig til FNs verdensmål. Forløbet afsluttes med en fælles videnfestival "verdens Bedste Løsninger LIVE!".

Vi har på biblioteket skelet til MITs PLIX program (plix, u.å.) med læringsforløb i makerspaces. Her ser vi et fremtidigt potentiale hvor elever, studerende og almindelige borgere kan indgå i videns- og læringsforløb i tværfaglige projektforløb. F.eks. kan man koble vores byhaver i Skovlunde til bygning af Food Computer (England, 2017) i makerspace.

Generelt er makerspace også en øjenåbner for de studerende. De udfordres i deres grundforståelse af et bibliotek som "kun" bøger, og viser en umiddelbar interesse i at bruge biblioteket mere. Vi har udviklet på vores studiemiljø for alle elever og studerende. Her spiller makerspace også en rolle i at tiltrække flere og nye brugere. Makerspace bruges bl.a. til at "pimpe" deres opgaver op, ved at udvikle prototyper, forbedre layout mv. 


\section{Referencer}

Arduino. (2018). Arduino. Lokaliseret 8/11/2018 på https://www.arduino.cc

Ballerup Kommune. (u.å.). Vision 2029. Lokaliseret 8/11/2018 på: https://ballerup.dk/om-

kommunen/politik/vision-2029

Cavalcanti, G. (2013, May 22). Is it a Hackerspace, Makerspace, TechShop, or FabLab? Make:

Lokaliseret 8/11/2018 på: https://makezine.com/2013/05/22/the-difference-between-

hackerspacesmakerspaces-techshops-and-fablabs/

Center for Undervisningsmidler. (2018). 21Skills. Lokaliseret 8/11/2018 på: http://info.21skills.dk/

DR. (u.å.). Ultra:bit. Lokaliseret 8/11/2018 på: https://www.dr.dk/skole/ultrabit

England, H. (2017, April 4). Build a personal food computer. Open Agriculture Initiative (OpenAg). Lokaliseret 8/11/2018 på: https://www.media.mit.edu/posts/build-a-food-computer/

Future Classroom Lab. (u.å.). Future classroom Lab.dk. Lokaliseret 8/11/2018 på:

http://www.futureclassroomlab.dk

Kulturministeriet. (2013) Bekendtgørelse af lov om biblioteksvirksomhed. LBK nr 100 af 30/01/2013. Lokaliseret 8/11/2018 på: https://www.retsinformation.dk/Forms/R0710.aspx?id=145152

Lego Group. (u.å.). Lego. Lokaliseret 8/11/2018 på: https://www.lego.com/en-us/mindstorms

Littlebits Electronics Inc. (u.å.). Making change makers. Lokaliseret 8/11/2018 på: https://littlebits.com

plix. (u.å.). plix. Lokaliseret 8/11/2018 på: https://plix.media.mit.edu/activities/

Ryan. (2016, April 3). LEGO art machine. The thinkering studio - sketchpad. Lokaliseret 8/11/2018 på: https://www.exploratorium.edu/tinkering/blog

SIV. (u.å.). Skolenivirkeligheden.dk: Danmark. Lokaliseret 8/11/2018 på: https://skolenivirkeligheden.dk/info$\underline{\text { om-siv }}$

SoftBank Robotics America, Inc. (2018). SoftBank Robotics. Lokaliseret 8/11/2018 på:

https://www.softbankrobotics.com/us/

Steen-Hansen, M. (2016, March 11). Digital Dannelse er en samfundsopgave - der kræver kompetencer fra vugge til grav. Biblioteksdebat - en blog om kultur, politik og bibliotek, hvor Michel kommenterer. Lokaliseret 8/11/2018 på: https://biblioteksdebat.blogspot.com/2016/03/digital-dannelse-er-en-samfundsopgave.html 